\title{
Manual synoptic climate classification for the East Coast of New England (USA) with an application to $\mathrm{PM}_{2.5}$ concentration
}

\author{
Barry D. Keim ${ }^{1, *}$, Loren David Meeker ${ }^{2}$, John F. Slater ${ }^{3}$ \\ ${ }^{1}$ Department of Geography and Anthropology, Louisiana State University, 327E Howe-Russell Science Complex, \\ Baton Rouge, Louisiana 70803, USA \\ ${ }^{2}$ Climate Change Research Center, University of New Hampshire, 56 College Road, Durham, New Hampshire 03824, USA \\ ${ }^{3}$ Division of Engineering, Math, and Science, Daniel Webster College, 20 University Drive, Nashua, New Hampshire 03063, USA
}

\begin{abstract}
This study presents a manual synoptic climate classification for the East Coast of New England with an application to regional pollution. New England weather was classified into 9 all-inclusive weather types: Canadian High, Modified High, Gulf of Maine Return, New England High, Atlantic Return, Frontal Atlantic Return, Frontal Overrunning-Continental, Frontal Overrunning-Marine, and Tropical Disturbance. Canadian High and Modified High weather are the dominant weather patterns at Boston, Massachusetts, while Tropical Disturbance, Gulf of Maine Return, and New England High weather types are the least frequent. Properties of the weather types were determined at 07:00 h Local Standard Time (LST) each day in Boston. The coldest and driest weather type is the Canadian High, while the hottest, most humid weather is generated by Frontal Atlantic Return. The synoptic weather classification system, applied to airborne fine particle mass concentrations with an aerodynamic diameter $\leq 2.5 \mu \mathrm{m}\left(\mathrm{PM}_{2.5}\right)$, showed significant differences in concentrations between weather types: transport from the north and northwest had low $\mathrm{PM}_{2.5}$, while transport from the south and southwest had high $\mathrm{PM}_{2.5}$ concentrations. This climate classification system also has potential applications ranging from studies of insect migration to analyses of climate change.
\end{abstract}

KEY WORDS: Synoptic climatology · New England · USA · Boston · Weather types · Applied climatology $\cdot \mathrm{PM}_{2.5}$

\section{INTRODUCTION}

One of the primary objectives in synoptic climatology is the classification of synoptic weather patterns into discriminate groups (Yarnal 1993). Once these groups, or 'weather types', are generated, they provide a useful baseline for environmental analysis, with widely ranging applications from studies of climate change (Kalkstein et al. 1990) to human mortality (Greene \& Kalkstein 1996). Recent methods in synoptic climatology have focused primarily on statistical derivation of synoptic weather patterns through various means including cluster analysis (e.g. Kidson 2000) and/or principal component analysis (e.g. Serra et al. 1999). This study presents a manual synoptic weather classification system for the East Coast of New England, for use in environmental analyses in the region.

Manual synoptic climate classifications have one primary advantage over statistically generated systems in that the weather class (or type) can be classified by the user through simple visual examination of a weather map. The primary disadvantage of manual systems is that the classification of long time periods can be prohibitively time consuming, although 2 long running manual synoptic classifications exist for the British Isles, dating back to 1861 (Lamb 1972), and New Orleans, Louisiana (USA), commencing in 1961 (Muller 1977). Yarnal (1993) has shown that manual weather typing is as effective a tool in environmental analysis as those derived through statistical means. 
An application to $\mathrm{PM}_{2.5}$ (atmospheric particles with an aerodynamic diameter $\leq 2.5 \mu \mathrm{m}$ ) at a rural site in New Hampshire is demonstrated. By connecting changes in synoptic weather conditions and changes in the concentration of $\mathrm{PM}_{2.5}$, this work will help to increase the understanding of some of the mechanisms behind aerosol variability in the northeastern USA, which in turn can reduce the uncertainty associated with climate forcing by aerosols.

\section{SCOPE AND METHODS}

New England weather and climate patterns are arguably among the most varied in the world. They include extremes of both high and low temperatures, large inter-diurnal changes in temperature, droughts, heavy rainfall, and blizzards (Zielinski \& Keim 2003). These great variations are influenced by many factors relating to the physical geographical setting, including the region's latitude near $45^{\circ} \mathrm{N}$, its coastal orientation, its continentality from its position within the westerlies, and its mountains. Since the weather patterns in the New England region are complex at fine scales, the aim of this classification system is to find order and structure at the synoptic scale, especially in the coastal zone in eastern New England, where the major cities of Boston, Massachusetts, and Portland, Maine, lie, and where the University of New Hampshire has a research program to understand transport of pollution.

Synoptic climatologies can be based on atmospheric pressure patterns or air-mass properties partitioned into classes based on manual, automated, or statistical procedures. Here, we apply an atmospheric pressurebased system using manual procedures similar to the synoptic classification developed for New Orleans and the central Gulf of Mexico coast by Muller (1977). This circulation-to-environment classification relies on the classic cyclone-anticyclone models with their centers of low and high pressure, respectively, and associated frontal boundaries, rain shields, wind vectors, etc. Any point within New England will have specific weather conditions because of its proximity to these cyclones and anticyclones. Therefore, given the scale of New England in proportion to these synoptic-scale weather systems, there will be instances when the entire region is experiencing the same weather type, or when the western portion of the region may have weather of a different type than the east, etc. Hence, applications of the classification must be done on a point location basis, rather than regionally as that of Davis \& Kalkstein (1990).

Although this synoptic classification is devised for the eastern coastal region of New England from Cape Cod to the border with Canada, it has broad applicabil- ity across the larger New England region. Boston, and Durham, New Hampshire (approximately $100 \mathrm{~km}$ north of Boston) were chosen as the foci for this analysis (Fig. 1). Boston is the largest city in New England and was chosen as the focal point for analysis of the frequency of the derived synoptic weather types and air-mass properties associated with them. Boston also has abundant high quality data for numerous weather variables, including temperature, dew point and wind speed, which should be representative of the relative frequencies and properties of the weather types. Boston was also chosen for its location on the East Coast, because this classification scheme will lend itself for subsequent use in analysis of the atmospheric chemistry in the rural region of Durham. The relative frequencies and properties of the weather types probably do not vary much between these 2 locations, given their proximity relative to the scale of cyclones and anticyclones. However, there are situations when a frontal boundary is located between the 2 sites, and delineates different weather types with substantive differences in air-mass properties. These differences are even greater for more distant locations such as Burlington, Vermont, but the general classification and its nomenclature are nevertheless applicable throughout New England.

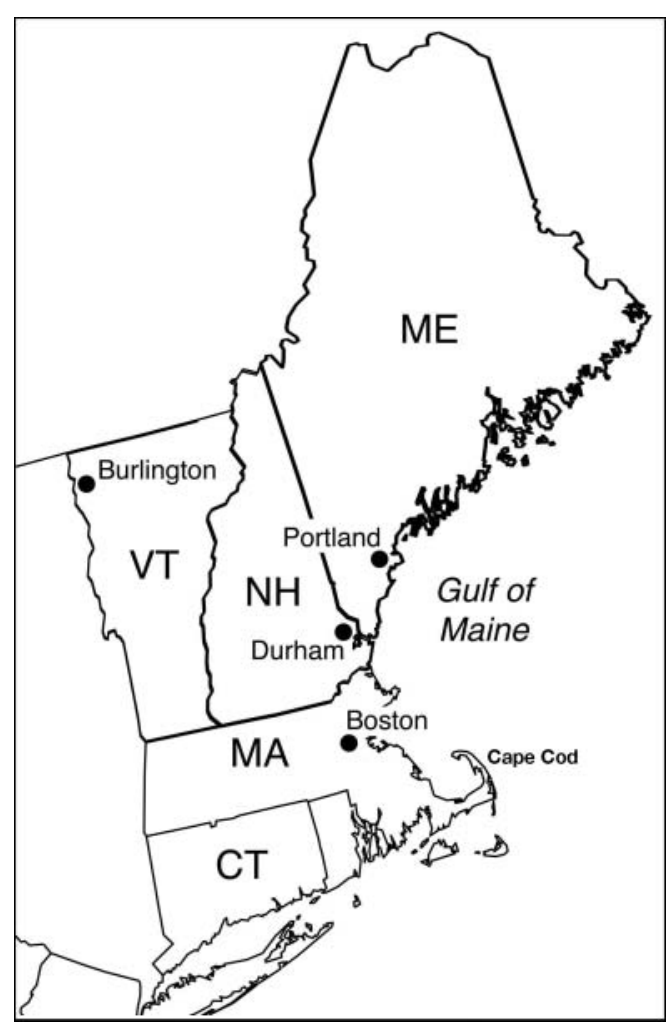

Fig. 1. Map of New England, USA, showing locations mentioned in the text 
The synoptic weather classification for the East Coast of New England was devised through examination of weather maps, mostly from the Daily Weather Maps series published by the National Oceanic and Atmospheric Administration (NOAA). At Boston, the time period and maps analyzed include the 07:00 $\mathrm{h}$ LST (12:00 h Greenwich Mean Time) daily weather map for the $5 \mathrm{yr}$ period from January 1995 through December 1999. This time period includes the El Niño event of late 1997/early 1998 and the 1999 La Niña event. However, the impacts of ENSO are minimal in New England (Ropelewski \& Halpert 1987, Halpert \& Ropelewski 1992, Bradbury et al. 2003) and these occurrences should not affect the basic derivation of the synoptic classification. This use of daily maps should yield a reliable climatology, because the frequencies of synoptic-scale pressure patterns are largely unaffected by diurnal variability.

This dataset was produced for initial assessment of weather types to analyze pollution transport into New England. Subsequent to this analysis, a separate dataset was derived for Durham, including analyses of 2 daily maps, at 07:00 and 19:00 h, for the summers of 2001 and 2002, to assess $\mathrm{PM}_{2.5}$.

\section{SYNOPTIC WEATHER TYPES}

Manual synoptic weather classification is formulated over an extended period of time through continuous examination of weather maps. Eventually, discernible types of weather emerge that result from particular recurring pressure patterns. From this process, 9 allinclusive weather types were generated for eastern New England, reflecting regional transport pathways into the region, potential for precipitation (which is not directly analyzed here), as well as air-mass characteristics, e.g. temperature, humidity, wind (Fig. 2). The selection of 9 discernible weather types, partitions of the classic cyclone/anticyclone model, closely follows the classification developed by Muller (1977), which included 8 weather types. The relative position of a location to the centers of high or low pressure and/or to the frontal boundaries determines the weather type. For example, when Boston is located in the warm sector of a cyclone, yet close to the cold frontal boundary, the weather type will be Frontal Atlantic Return. At the same time, Concord may lie on the other side of the cold front, and hence the classification may be either Frontal Overrunning-Continental or Canadian High, depending on the extent of cloud cover behind the cold front; if Concord is positioned beyond the cloud shield, it will be classified as Canadian High. There is variability within each weather type (Fig. 2), but the goal is to create a meaningful number of classes that are use-

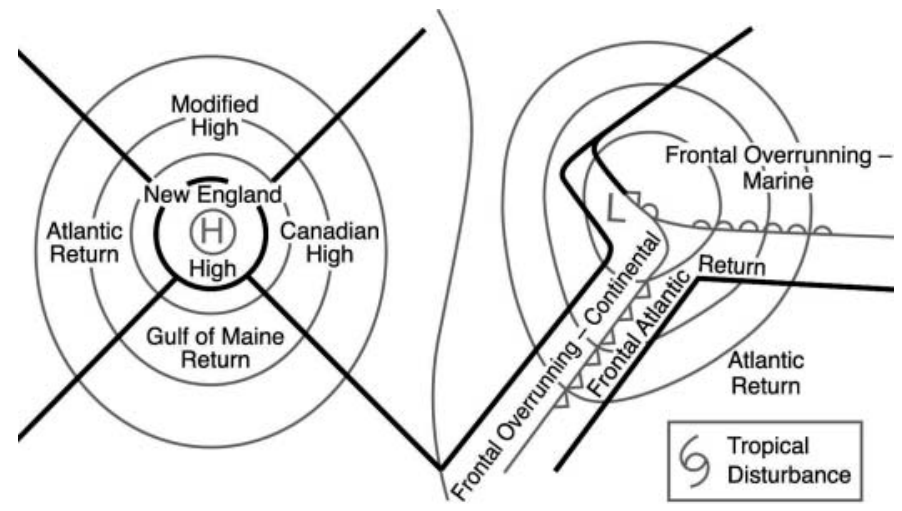

Fig. 2. Circulation-to-environment synoptic weather classification for the East Coast of New England

ful for environmental analysis. The geographical space depicted in Fig. 2 can be parsed into virtually any number of classes, but the 9-class system follows the example of Muller (1977), producing a system with potentially meaningful applications in the region, especially regarding air pollution.

Canadian High (CH) (Fig. 3). This weather type occurs when the region falls on the eastern side of an anticyclone, whereas the area of high pressure is usually situated northwest or west of New England (e.g. over or just north of the Great Lakes). This pressure pattern steers northerly or northwesterly winds into the region, delivering Canadian air. Conditions in this weather type are mostly fair, and in winter this weather type delivers the lowest temperatures and driest air to the region.

Modified High (MH) (Fig. 4). MH weather occurs on the northern side of an anticyclone. As an anticyclone of Canadian origin drifts south or southeastward, the center of the high pressure complex becomes situated in the American Midwest, bringing westerly winds into New England. These anticyclones typically have had a long trajectory into the central United States and are therefore modified through slight increases in temperature and humidity, when compared to $\mathrm{CH}$. $\mathrm{MH}$ can also be of Pacific origin. This is a fair weather type with low temperatures in winter, but it is milder than $\mathrm{CH}$.

Gulf of Maine Return (GMR) (Fig. 5). This weather type occurs when a location falls in the southern quadrant of an anticyclone. When Canadian high pressure moves north and east of New England, winds shift to the northeast or east, advecting maritime polar (mP) air from the Gulf of Maine into the region. Typically, the weather is fair and humid, but can sometimes produce ocean-effect snow in the coastal zone, especially over Cape Cod.

New England High (NEH) (Fig. 6). Occasionally, a dome of high pressure will track directly over New England. When the high is centered over the area, 
winds are weak and from changing directions across the region. NEH are also classified when there is little or no pressure gradient at all and the regional response is the same as when the high pressure complex is directly overhead. Fair weather is common in these instances.

Atlantic Return (AR) (Fig. 7). AR weather occurs in the return flow of an anticyclone (on the western side), and/or within the warm sector of a cyclone. When high pressure is positioned to the southeast of New England, just offshore from the mid-Atlantic states, the pressure pattern steers southwest, south, or even southeasterly winds into the region. This weather type typically produces high temperatures and humid weather. AR is mostly a fair weather type, but scattered afternoon thunderstorms are common in summer and early fall.

Frontal Atlantic Return (FAR) (Fig. 8). As a midlatitude cyclone approaches New England from the west, the region is positioned in the warm sector of the cyclone, with south or southwesterly flow. Advection is similar to the AR weather type, but frontal boundaries and instability influence the region. This weather type typically produces cloudiness and rain, even in winter.

Frontal Overrunning-Continental (FOR-C) (Fig. 9). This weather type occurs in a narrow zone behind a passing cold front. After the passage of a cold front, high pressure typically builds in from the west or northwest, driving continental winds into the area from the northwest. Just after the surface front clears the area, however, tropical air often overrides the continental polar air at the surface, causing clouds and precipitation. In winter, the precipitation type is usually snow.

Frontal Overrunning-Marine (FOR-M) (Fig. 10). FOR-M weather occurs in the northeastern sector of a cyclone. When low pressure is positioned either offshore or south of New England, the region experiences easterly winds (marine in origin) from the Gulf of Maine, although maritime tropical (mT) air overrides this relatively colder air from the south. This weather type can produce rain, and prolonged snowfall is common in winter. This is the primary weather type for coastal northeasters.

Tropical Disturbance (TD) (Fig. 11). Hurricanes and tropical storms can occasionally make it to New England, delivering heavy rainfall and high winds. Wind direction is completely variable, depending on the storm path. More often than not, New England receives remnant tropical systems that produce rain, but with gentle winds.

The basic classification system is the same as that proposed by Muller (1977), even if there are obvious differences in weather types between New England and Louisiana. The differences between this synoptic

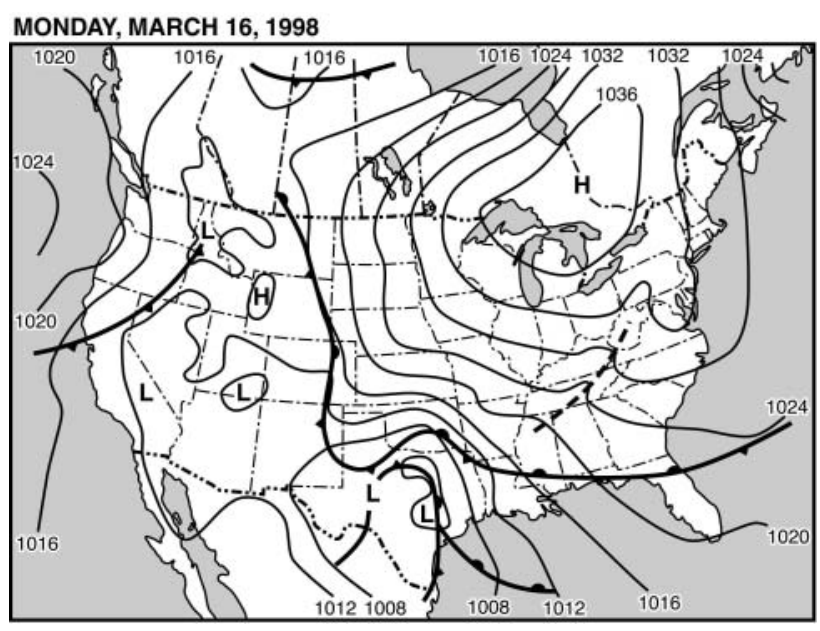

Fig. 3. Canadian High (CH) weather type on March 16, 1998

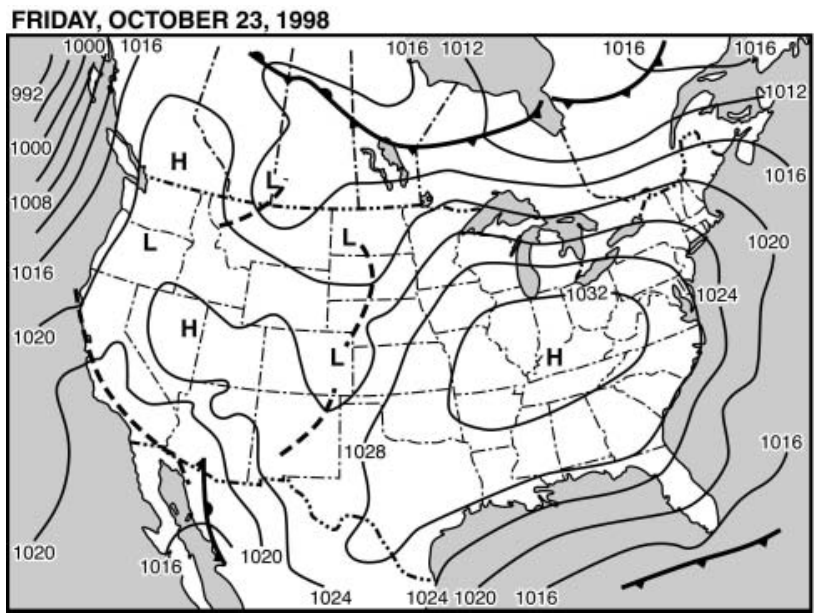

Fig. 4. Modified High (MH) weather type on October 23, 1998

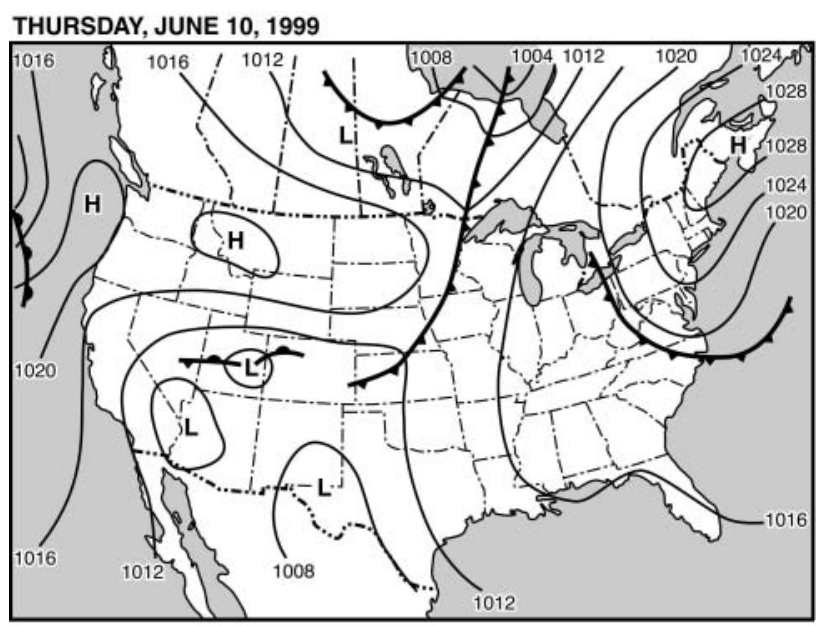

Fig. 5. Gulf of Maine Return (GMR) weather type on June 10, 1999 


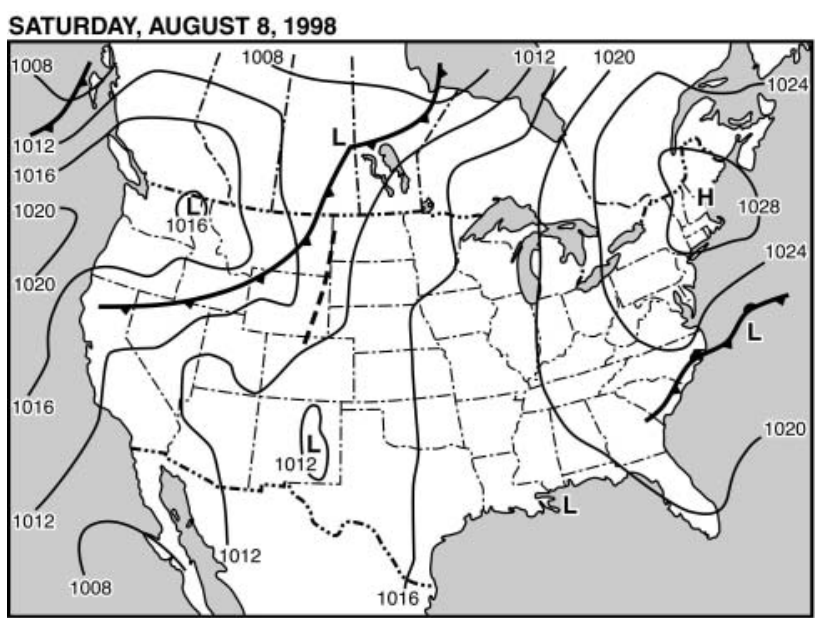

Fig. 6. New England High (NEH) weather type on August 8, 1998

TUESDAY, JUNE 1, 1999

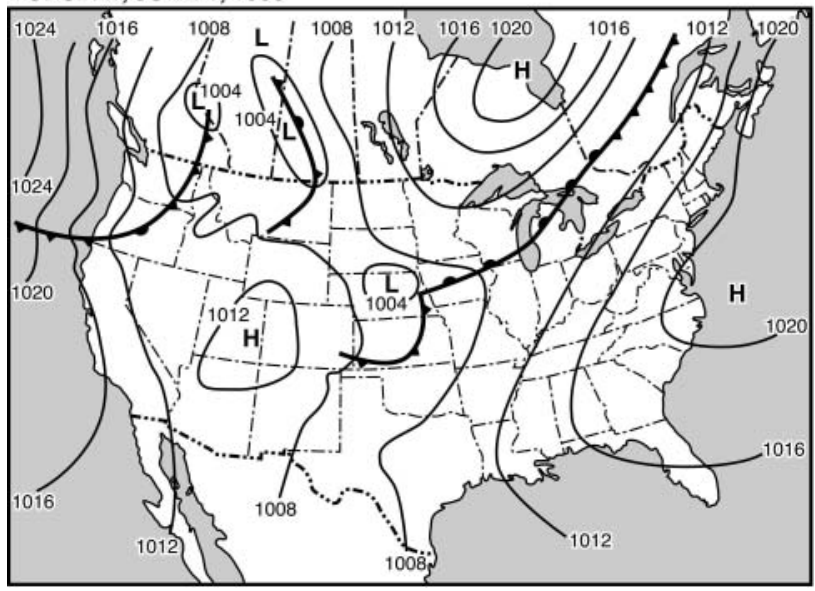

Fig. 7. Atlantic Return (AR) weather type on June 1, 1999

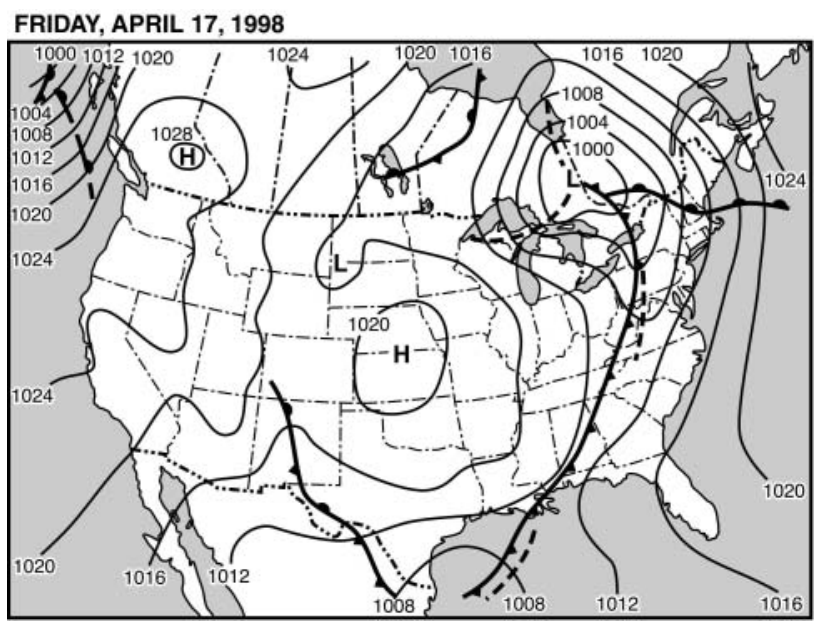

Fig. 8. Frontal Atlantic Return (FAR) weather type on April 17, 1998

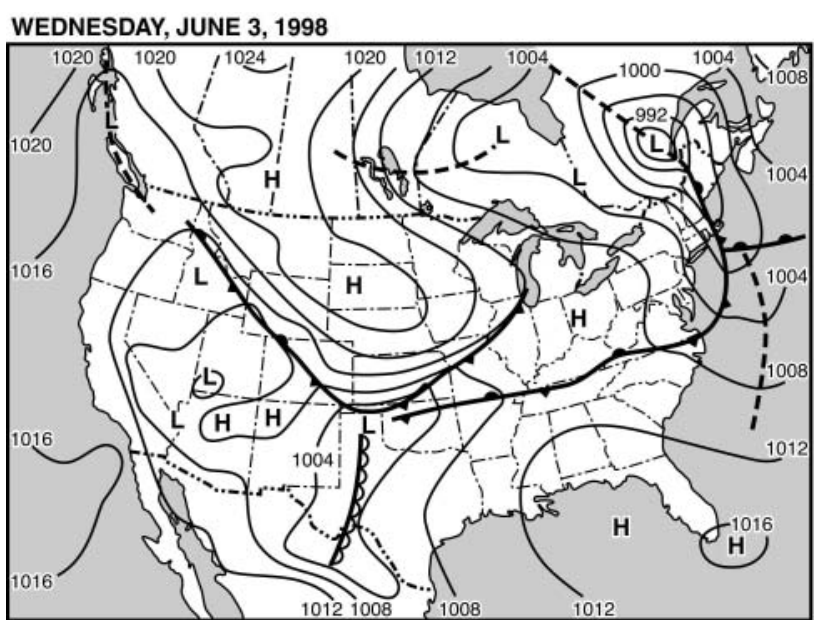

Fig. 9. Frontal Overrunning-Continental (FOR-C) weather type on June 3, 1998

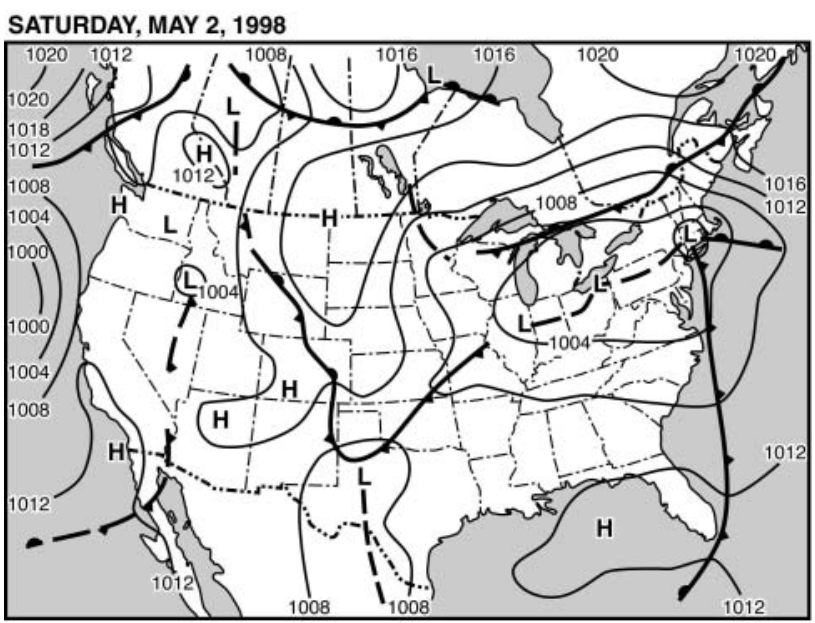

Fig. 10. Frontal Overrunning-Marine (FOR-M) weather type on May 2, 1998

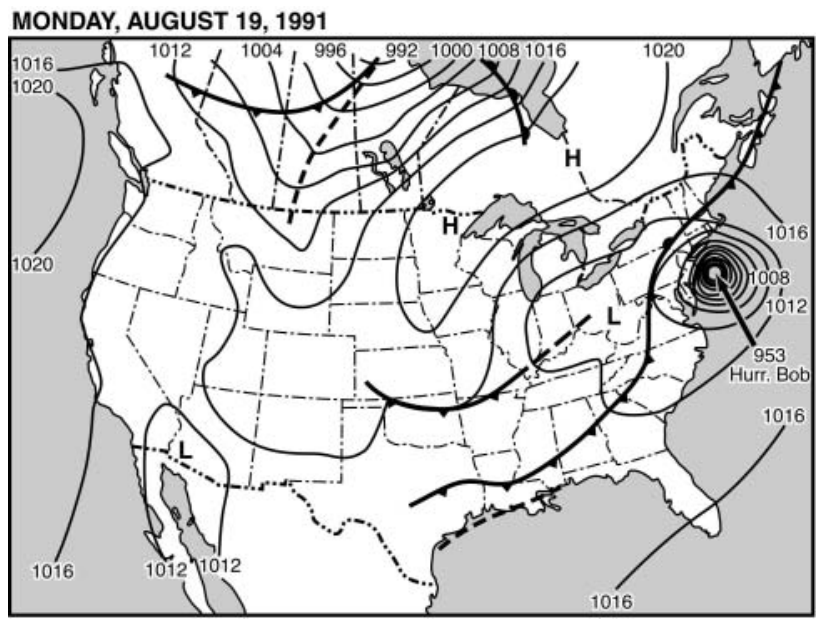

Fig. 11. Tropical Disturbance (TD) weather type on August 19, 1991 
climatology and the Muller system are subtle, yet these subtleties may assist in understanding the varying transport of pollution into the region. For example, New England frequently experiences frontal overrunning conditions with surface winds either from the northwest (FOR-C with continental air at the surface) or east (FOR-M with marine air at the surface), representing 2 completely different circumstances for surface advection that may be important in environmental analyses. The Muller system only includes 1 frontal overrunning class, but 2 classes of high pressure system (Continental High and Pacific High), a distinction not considered important in New England. One other notable difference with this system is the inclusion of $\mathrm{NEH}$ weather, since anticyclones frequently migrate directly over the region, a situation which is not common in Louisiana.

\section{ANALYSIS AND DISCUSSION}

Using the Daily Weather Map series, each day at 07:00 h LST from 1995 to 1999 was classified into 1 of the 9 all-inclusive weather types, and air-mass properties, frequencies and seasonality, and transition probabilities are examined.

\subsection{Air-mass properties by synoptic weather type}

To acquire a sense of the air-mass properties of each weather type, meteorological data at 07:00 h LST were extracted for Boston and averaged for each weather type for January and July (Table 1). Some sample sizes are rather limited, but their averages are consistent with expectations. To demonstrate that these air-mass properties represent differing populations, the data were tested using a 1-way MANOVA (Rencher 1998). The 2 types with the lowest January count (GMR and NEH), were eliminated from the analysis described below. For each month (January and July), the multivariate test indicated highly significant differences among weather types $(\mathrm{p}<$ 0.0001). To further explore differences indicated by MANOVA, pairwise multivariate tests for equality between weather types were conducted. The significance values for the pairwise tests shown in Table 2 indicate that, in most cases, air-mass properties are significantly different between weather types. Surprisingly, results for January are not as compelling as July, although Table 1 shows smaller variances between weather types in both wind speed and visibility in January. Other factors contributing to this result may be related to the time of day $(07: 00 \mathrm{~h}$ LST) under analysis and the propensity for snow cover. In January, highly insignificant differences are found between FAR and AR, both of which are characterized by south or southwesterly advection within the warm sector of a cyclone; hence the similarity is expected. Air-mass properties for AR are also not dissimilar from FOR-M, both of which are dominated by advection off the ocean. Overall, these results support the synoptic classification presented here and the subsequent analysis of $\mathrm{PM}_{2.5}$ will further demonstrate differences in the synoptic weather types, even when the air-mass properties do

Table 1. Average air-mass properties by synoptic weather type at Boston for 1995 to 1999 at 07:00 h LST

\begin{tabular}{|c|c|c|c|c|c|c|}
\hline & $\mathrm{N}$ & $\begin{array}{c}\text { Temperature } \\
\left({ }^{\circ} \mathrm{C}\right)\end{array}$ & $\begin{array}{c}\text { Dew point } \\
\left({ }^{\circ} \mathrm{C}\right)\end{array}$ & $\begin{array}{c}\text { Relative } \\
\text { humidity (\%) }\end{array}$ & $\begin{array}{c}\text { Wind speed } \\
\left(\mathrm{km} \mathrm{h}^{-1}\right)\end{array}$ & $\begin{array}{l}\text { Visibility } \\
(\mathrm{km})\end{array}$ \\
\hline \multicolumn{7}{|l|}{ January } \\
\hline Canadian High $(\mathrm{CH})$ & 36 & -7 & -12 & 64 & 19 & 18 \\
\hline Modified High (MH) & 23 & -4 & -11 & 59 & 19 & 18 \\
\hline Gulf of Maine Return (GMR) & 2 & -1 & -3 & 86 & 18 & 11 \\
\hline New England High (NEH) & 4 & 0 & -4 & 75 & 11 & 18 \\
\hline Atlantic Return (AR) & 15 & 1 & -3 & 78 & 16 & 14 \\
\hline Frontal Atlantic Return (FAR) & 26 & 3 & 1 & 82 & 19 & 16 \\
\hline Frontal Overrunning-Continental (FOR-C) & 33 & -1 & -4 & 80 & 16 & 11 \\
\hline Frontal Overrunning-Marine (FOR-M) & 16 & 3 & 1 & 88 & 15 & 10 \\
\hline \multicolumn{7}{|l|}{ July } \\
\hline Canadian High $(\mathrm{CH})$ & 28 & 21 & 13 & 63 & 16 & 18 \\
\hline Modified High (MH) & 33 & 23 & 15 & 63 & 13 & 18 \\
\hline Gulf of Maine Return (GMR) & 7 & 18 & 16 & 86 & 10 & 16 \\
\hline New England High (NEH) & 10 & 21 & 14 & 69 & 8 & 14 \\
\hline Atlantic Return (AR) & 28 & 23 & 18 & 72 & 13 & 13 \\
\hline Frontal Atlantic Return (FAR) & 24 & 23 & 19 & 82 & 13 & 11 \\
\hline Frontal Overrunning-Continental (FOR-C) & 8 & 22 & 17 & 75 & 11 & 13 \\
\hline Frontal Overrunning-Marine (FOR-M) & 16 & 20 & 18 & 91 & 10 & 6 \\
\hline
\end{tabular}


Table 2. Significance values of multivariate pairwise mean comparisons for weather types at Boston. See Table 1 for abbreviations. Bold values are significant at $\mathrm{p} \leq 0.05$. - insufficient sample size for analysis

\begin{tabular}{|lccccccc|}
\hline & MH & GMR & NEH & AR & FAR & FOR-C & FOR-M \\
\hline January & & & & & & & \\
CH & 0.0924 & - & - & $\mathbf{0 . 0 0 2 4}$ & $\mathbf{0 . 0 0 0 0}$ & $\mathbf{0 . 0 0 0 0}$ & $\mathbf{0 . 0 0 0 0}$ \\
MH & & - & - & $\mathbf{0 . 0 0 4 8}$ & $\mathbf{0 . 0 0 0 0}$ & $\mathbf{0 . 0 0 0 2}$ & $\mathbf{0 . 0 0 0 0}$ \\
GMR & & & - & - & - & - & - \\
NEH & & & & - & - & - & - \\
AR & & & & & 0.3626 & 0.8198 & 0.5121 \\
FAR & & & & & & $\mathbf{0 . 0 0 2 3}$ & 0.0757 \\
FOR-C & & & & & & & 0.0906 \\
July & & & & & & & \\
CH & 0.0628 & $\mathbf{0 . 0 0 1}$ & $\mathbf{0 . 0 4 2 1}$ & $\mathbf{0 . 0 0 0 0}$ & $\mathbf{0 . 0 0 0 0}$ & $\mathbf{0 . 0 2 6 7}$ & $\mathbf{0 . 0 0 0 0}$ \\
MH & & $\mathbf{0 . 0 0 0 0}$ & $\mathbf{0 . 0 0 1 1}$ & $\mathbf{0 . 0 0 0 4}$ & $\mathbf{0 . 0 0 0 0}$ & $\mathbf{0 . 0 4 7 0}$ & $\mathbf{0 . 0 0 0 0}$ \\
GMR & & & $\mathbf{0 . 0 3 1 2}$ & $\mathbf{0 . 0 0 6 1}$ & $\mathbf{0 . 0 0 3 0}$ & 0.3716 & 0.3000 \\
NEH & & & & $\mathbf{0 . 0 0 2 5}$ & $\mathbf{0 . 0 0 0 0}$ & $\mathbf{0 . 0 2 2 3}$ & $\mathbf{0 . 0 0 0 3}$ \\
AR & & & & & $\mathbf{0 . 0 4 2 1}$ & 0.7795 & $\mathbf{0 . 0 0 0 0}$ \\
FAR & & & & & & $\mathbf{0 . 0 0 9 6}$ & $\mathbf{0 . 0 0 8 9}$ \\
FOR-C & & & & & & & $\mathbf{0 . 0 3 2 9}$ \\
\hline
\end{tabular}

ated with high pressure over the American Midwest. Furthermore, the air is warmed adiabatically as it descends from the mountains in western New England to the coastal zone. Some of the highest temperatures ever recorded in New England have come during times of westerly winds in summer. Dew points and relative humidity are low with high pressure weather $(\mathrm{CH}, \mathrm{MH}$ and $\mathrm{NEH})$ and are higher with FAR, FOR-M and AR, respectively. Wind speeds are generally lower in summer than in winter, with the greatest wind speeds again associated with $\mathrm{CH}$ weather. Visibility is greatest under $\mathrm{CH}$ and $\mathrm{MH}$ conditions, and lowest during FOR-M weather. not differ significantly, e.g. GMR from FOR-C and FOR-M.

In January, the average 07:00 h LST temperature is lowest during the $\mathrm{CH}$ and $\mathrm{MH}$ weather types, respectively, with transport of continental polar (cP) or modified $\mathrm{cP}$ air masses from Canada. The highest temperatures at 07:00 h LST in January are found with FAR, FOR-M, and AR weather types, respectively. If the afternoon was examined, AR weather would have higher temperatures, since the 07:00 h LST temperature follows a night of radiational cooling under mostly clear skies. Temperatures during FOR-M largely reflect the offshore sea surface temperature, which remains higher than the adjacent land temperature at this time of year. Dew points and relative humidity are low with the weather types controlled by high pressure $(\mathrm{CH}, \mathrm{MH}$ and $\mathrm{NEH}$, respectively) and are humid with advection from the east (FOR-M, GMR) or south (FAR, AR). Wind speeds are highest with $\mathrm{CH}, \mathrm{MH}$ and FAR weather, while visibility is highest with the suite of high pressure weather types ( $\mathrm{CH}, \mathrm{MH}$ and $\mathrm{NEH})$.

In July, the lowest morning temperatures occur with advection off the Gulf of Maine, including the FOR-M and GMR weather types, which again reflect sea surface temperatures that are lower than land temperatures at this time of year. The highest temperatures occur with FAR, AR and MH weather. The southerly advection associated with FAR, and AR weather make the higher temperatures unremarkable. However, the presence of higher temperatures under $\mathrm{MH}$ conditions probably implies that $\mathrm{mT}$ air from the Gulf of Mexico and Caribbean is being transported northward into the Great Plains of the United States and redirected eastward to New England by the pressure gradient associ-

\subsection{Weather type frequencies}

$\mathrm{CH}$ weather was the most frequent type at Boston during the study period, with $>25 \%$ of all days falling into this class; $\mathrm{MH}$ weather was second at $16 \%$ (Table 3). The relatively low percentage of TD days $(<1 \%)$ is not surprising (Louisiana, which is much more vulnerable to tropical storms and hurricanes than New England, had only $3 \%$ of all hours classified as 'tropical disturbance' by Muller \& Willis 1983). Weather type frequencies by month also show seasonality. $\mathrm{CH}$ weather was the most frequent weather type in 10 of the 12 months, and MH was the most frequent in July and October. $\mathrm{CH}$ weather also shows higher frequencies in late winter and early spring, with slightly lower frequencies in late spring and early summer. This is consistent with the findings of Bradbury et al. (2002), who noted an eastward migration of the $500 \mathrm{hPa}$ United States East Coast Trough from winter to early spring, which would be associated with the $\mathrm{CH}$ weather type. $\mathrm{MH}$ shows little seasonality. GMR weather is relatively rare, with minimum frequencies from November through January and higher occurrence rates from May through October. The low frequencies in winter are presumably related to the expansion and configuration of the circumpolar vortex. After a cold air outbreak in New England, meridional flow will tend to steer Canadian anticyclones to the southeast, rather than due east (north of New England). NEH shows little seasonality other than relatively low occurrence rates in winter. AR and FAR weather show a clearer signal with relatively high occurrence rates in summer. The southerly advection associated with these weather types is reinforced by 
Table 3. Monthly and annual frequency (\%) of each synoptic weather type at Boston. The weather type of greatest frequency for each month is bold and the month of highest frequency for each weather type is italic. See Table 1 for abbreviations

\begin{tabular}{|c|c|c|c|c|c|c|c|c|c|}
\hline & $\mathrm{CH}$ & $\mathrm{MH}$ & GMR & $\mathrm{NEH}$ & $\mathrm{AR}$ & FAR & $\mathrm{FOR}-\mathrm{C}$ & FOR-M & TD \\
\hline January & 23.2 & 14.8 & 1.3 & 2.6 & 9.7 & 16.8 & 21.3 & 10.3 & 0 \\
\hline February & 30.5 & 17.7 & 2.1 & 5.7 & 9.2 & 9.2 & 19.9 & 5.7 & 0 \\
\hline March & 31.0 & 12.3 & 2.6 & 5.8 & 11.6 & 12.3 & 15.5 & 9.0 & 0 \\
\hline April & 34.0 & 14.0 & 2.0 & 8.7 & 7.3 & 12.0 & 12.7 & 9.3 & 0 \\
\hline May & 20.7 & 15.5 & 9.7 & 8.4 & 10.3 & 9.0 & 9.0 & 17.4 & 0 \\
\hline June & 20.7 & 14.7 & 7.3 & 6.7 & 19.3 & 12.0 & 10.0 & 9.3 & 0 \\
\hline July & 18.1 & 21.3 & 4.5 & 6.5 & 18.1 & 15.5 & 5.2 & 10.3 & 0.6 \\
\hline August & 29.0 & 12.3 & 1.3 & 8.4 & 12.9 & 15.5 & 7.1 & 11.0 & 2.6 \\
\hline September & 23.3 & 12.0 & 4.7 & 8.0 & 16.0 & 12.0 & 11.3 & 6.0 & 6.7 \\
\hline October & 20.7 & 22.6 & 4.5 & 8.4 & 14.8 & 10.3 & 11.6 & 7.1 & 0 \\
\hline November & 29.3 & 16.7 & 1.3 & 2.0 & 12.0 & 12.7 & 16.0 & 10.0 & 0 \\
\hline December & 26.5 & 21.3 & 1.3 & 3.2 & 12.3 & 15.5 & 14.8 & 5.16 & 0 \\
\hline Annual mean & 25.5 & 16.3 & 3.6 & 6.2 & 12.8 & 12.8 & 12.8 & 9.3 & 0.8 \\
\hline
\end{tabular}

Table 4. Frequency (no. of days) of each weather type at Boston for each year, and for summer (JJA) only. See Table 1 for abbreviations

\begin{tabular}{|lrrrrrrrrr|}
\hline \multicolumn{2}{c}{ CH } & MH & GMR & NEH & AR & FAR & FOR-C FOR-M & TD \\
\hline Annual & & & & & & & & & \\
1995 & 118 & 57 & 10 & 28 & 36 & 50 & 36 & 28 & 2 \\
1996 & 82 & 54 & 17 & 29 & 50 & 46 & 46 & 38 & 4 \\
1997 & 107 & 70 & 11 & 20 & 45 & 44 & 44 & 23 & 1 \\
1998 & 87 & 57 & 13 & 17 & 44 & 51 & 50 & 43 & 3 \\
1999 & 72 & 59 & 14 & 19 & 59 & 42 & 58 & 37 & 5 \\
Summer only & & & & & & & & \\
1995 & 27 & 15 & 3 & 9 & 9 & 17 & 3 & 7 & 2 \\
1996 & 17 & 13 & 5 & 8 & 20 & 13 & 2 & 14 & 0 \\
1997 & 27 & 21 & 4 & 6 & 11 & 9 & 7 & 6 & 1 \\
1998 & 18 & 10 & 4 & 6 & 14 & 17 & 12 & 9 & 2 \\
1999 & 15 & 15 & 4 & 4 & 23 & 10 & 10 & 11 & 0 \\
\hline
\end{tabular}

ences in weather type counts during the other seasons were not significant. These results suggest that between 1995 and 1999, summers were more variable than the other seasons.

\subsection{Transitions in synoptic weather types}

Transitions in weather types were analyzed to determine the temporal sequencing of weather patterns. Twostep transition probabilities estimated the probability of weather type occurrence on the day following a given weather type (Table 5). In the case of $\mathrm{CH}$ for example, the day after also tends to be $\mathrm{CH}$ (in $40 \%$ of the cases). The next highest transition probability for $\mathrm{CH}$ is $\mathrm{MH}$, with TD being the least likely tran- strong Bermuda High circulation at that time of year. FOR-C weather clearly declines in frequency during summer. Finally, TD weather follows the pattern of the hurricane season, with a gradual increase in activity in July and August, with a peak in September.

Weather type counts for each year show large variations (Table 4). For example, annual counts of $\mathrm{CH}$ weather range from 72 in 1999 (20\%) to 118 in 1995 (32\%), a difference of $12 \%$ in annual frequency. This and other differences were tested for significance using the $\chi^{2}$ test. Results imply that the differences among the years are significant $\left(\chi^{2}=49.6, \mathrm{p}<\right.$ $0.05)$. Seasonal analysis of these data shows that most of the variability between years took place in summer (Table 4) $\left(\chi^{2}=41.9, \mathrm{p}<0.05\right)$. Differ-
Table 5. Estimated transition probabilities of each synoptic weather type [SWT $(n+1)$ / SWT (n)] at Boston, based on 5 yr daily data from 1995 to 1999. The highest probable transition from one weather type to another is denoted in bold, and transition to the same weather type is denoted in italics. See Table 1 for abbreviations

\begin{tabular}{|lccccccccc|}
\hline & CH & MH & GMR & NEH & AR & FAR & FOR-C & FOR-M & TD \\
\hline CH & 0.40 & 0.18 & 0.15 & 0.09 & 0.13 & $\mathbf{0 . 2 7}$ & $\mathbf{0 . 3 8}$ & 0.14 & 0.13 \\
MH & $\mathbf{0 . 1 3}$ & 0.30 & 0.00 & 0.09 & 0.14 & 0.20 & 0.16 & 0.11 & 0.13 \\
GMR & 0.04 & 0.01 & 0.15 & 0.08 & 0.04 & 0.01 & 0.03 & 0.03 & 0.07 \\
NEH & 0.11 & 0.09 & 0.06 & 0.09 & 0.02 & 0.03 & 0.03 & 0.03 & 0.13 \\
AR & 0.11 & $\mathbf{0 . 1 9}$ & 0.14 & $\mathbf{0 . 2 7}$ & 0.19 & 0.06 & 0.04 & 0.12 & 0.07 \\
FAR & 0.07 & 0.13 & 0.14 & 0.18 & $\mathbf{0 . 2 6}$ & 0.14 & 0.05 & 0.16 & 0.07 \\
FOR-C & 0.07 & 0.06 & 0.14 & 0.08 & 0.15 & 0.18 & 0.19 & $\mathbf{0 . 2 4}$ & 0.07 \\
FOR-M & 0.08 & 0.03 & $\mathbf{0 . 1 8}$ & 0.12 & 0.07 & 0.11 & 0.11 & 0.17 & 0.00 \\
TD & 0.01 & 0.00 & 0.03 & 0.01 & 0.00 & 0.00 & 0.01 & 0.00 & 0.33 \\
& & & & & & & & & \\
\hline
\end{tabular}


sition weather type. $\mathrm{MH}$ also tends to persist for more than $1 \mathrm{~d}$, and most frequently the day following a $\mathrm{MH}$ day is another $\mathrm{MH}$. However, the next highest transition frequency is AR. In essence, these transition probabilities build a common sequence of weather types as follows: $\mathrm{CH}>\mathrm{MH}>\mathrm{AR}>\mathrm{FAR}>\mathrm{CH}$, as the train of cyclones and anticyclones moves from west to east. FAR also frequently transitions to FOR-C, then back to $\mathrm{CH}$. These transition probabilities also demonstrate that FOR-C and FOR-M tend to transition back and forth. Note that these are only tendencies in the weather type transitions. Table 5 demonstrates thatbarring TD-each weather type has been followed by every other possible weather type at one time or another, and that continuous predictable sequences are not common. However, we tested the data with the $\chi^{2}$ test for independence and concluded that the data are not randomly distributed; hence there is an overriding structure to the pattern that follows dynamical considerations $(p \leq 0.05)$. Sequencing of weather types in this manner is important for understanding the frequencies and magnitudes of precipitation events (Hay et al. 1991) and probably has other applications as well, including interpretation of acute air pollution episodes.

\subsection{Weather type indices}

To evaluate weather/climate conditions and environmental responses, synoptic weather types can be combined to form indices (Muller 1977). In this case, we devised 3 indices: (1) the High Pressure Index (HPI), which is a combination of $\mathrm{CH}, \mathrm{MH}, \mathrm{GMR}$, and $\mathrm{NEH}_{\text {; }}$ (2) the (WWI) including $\mathrm{AR}$ and FAR; and (3) the (SI), including FAR, FOR-C, FOR-M and TD (Table 6). On average, Boston experiences HPI weather on over half of all days $(51.5 \%)$, which corresponds well with Boston's normal number of clear and partly cloudy days (55.3\%). SI weather occurs on about one-third of all days, which also corresponds well with the normal number of rain days. Inter-

Table 6. Synoptic weather type indices (\%) at Boston. HPI: High Pressure Index; WWI: Warm Weather Index; SI: Storminess Index

\begin{tabular}{|llll|}
\hline & HPI & WWI & SI \\
\hline 1995 & 58.4 & 23.6 & 31.8 \\
1996 & 49.7 & 26.2 & 36.6 \\
1997 & 57.0 & 24.4 & 30.7 \\
1998 & 47.7 & 26.0 & 40.3 \\
1999 & 44.9 & 27.7 & 38.9 \\
Mean & 51.5 & 25.6 & 35.7 \\
\hline
\end{tabular}

annual variations between the 5 years were tested using the $\chi^{2}$ test, which showed that the counts of these 3 indices were significantly different between years $\left(\chi^{2}=18.8, \mathrm{p}<0.05\right)$. The years 1995 and 1997 have more HPI and less SI than expected, while 1998 and 1999 have less HPI and more SI than expected. Given the relatively low HPI (which are generally cold weather types) for 1998 and 1999, it is not surprising that these years had the highest average temperatures. Also, the anomalously high SI in 1998 corresponds with the wettest of the 5 years.

\section{APPLICATION TO $\mathrm{PM}_{2.5}$ CONCENTRATION}

Synoptic weather patterns often serve as transportation mechanisms for pollution and other chemical constituents (e.g. Comrie 1996). One such type of pollution that has received attention recently is fine airborne particulate matter $\leq 2.5 \mu \mathrm{m}\left(\mathrm{PM}_{2.5}\right)$. The scattering and absorption of short-wavelength solar radiation by atmospheric aerosol particles directly affects the radiative balance of the Earth. Recent model estimates of the direct industrial aerosol radiative forcing range between -0.07 and $-1.24 \mathrm{~W} \mathrm{~m}^{-2}$, compared to the estimated range of +2.19 to $+2.67 \mathrm{~W} \mathrm{~m}^{-2}$ due to the radiative forcing of anthropogenic greenhouse gases (IPCC 2001). One of the main causes of the large uncertainty associated with direct aerosol radiative forcing is variations in aerosol properties in both time and space (e.g. Schwartz \& Andreae 1996). The northeastern USA is one region where direct anthropogenic aerosol radiative forcing is highly variable and typically exceeds that of anthropogenic greenhouse gases (e.g. Grant et al. 1999).

Along with its impact on climate by perturbing the Earth's radiation budget, the scattering and absorption of short-wavelength solar radiation by fine particles is the major cause for reduced visibility in many parts of the USA (e.g. Malm et al. 1994). Additionally, epidemiological evidence supports a link between adverse human health effects and fine particles, primarily because small particles have the ability to penetrate into sensitive regions of the human respiratory tract (Dockery et al. 1993).

For these reasons, we conducted a pilot study to examine relationships between synoptic weather patterns and $\mathrm{PM}_{2.5}$ mass concentration during the summer (JJA) of 2001 and 2002; we combined these 2 datasets to increase our sample size. We chose summer months because this is the time of year when aerosol concentrations are at their highest levels in New England (e.g. Jordan et al. 2000). This study was set in Durham (Fig. 1), in the coastal region of New England, $100 \mathrm{~km}$ north of Boston. 
Table 7. Summer (JJA) 2001-2002 daily average airborne fine particle mass concentrations $\left(\mathrm{PM}_{2.5}\right.$ in $\left.\mu \mathrm{g} \mathrm{m}^{-3}\right)$ in Durham, New Hampshire, by synoptic weather type

\begin{tabular}{|lccr|}
\hline & Mean \pm SD & Median & $\mathrm{N}$ \\
\hline CH & $9.8 \pm 6.8$ & 7.3 & 16 \\
MH & $10.7 \pm 7.9$ & 6.5 & 5 \\
GMR & $7.9 \pm 4.7$ & 7.9 & 2 \\
NEH & $14.7 \pm 1.1$ & 14.7 & 2 \\
AR & $27.5 \pm 10.1$ & 26.4 & 17 \\
FAR & $18.1 \pm 8.2$ & 17.5 & 5 \\
FOR-C & $22.0 \pm 9.4$ & 22.6 & 4 \\
FOR-M & $22.5 \pm 9.9$ & 19.2 & 11 \\
\hline
\end{tabular}

To measure $\mathrm{PM}_{2.5}$, we used a Continuous Ambient Mass Monitor (CAMM; Andersen Instruments); the measurement principle is described in detail by Babich et al. (2000). Different measurement methods of $\mathrm{PM}_{2.5}$ are outlined in US EPA (1997a) and the standard of $24 \mathrm{~h}$ $\mathrm{PM}_{2.5}$ measurements is set forth in US EPA (1997b). The CAMM has a detection limit of $3 \mu \mathrm{g} \mathrm{m}^{-3}$ for $\mathrm{PM}_{2.5}$ concentrations averaged over $1 \mathrm{~h}$. To comply with US EPA guidelines, we averaged 24 one-hour measurements, as demonstrated by Babich et al. (2000), during each of the days during the summers of 2001 and 2002 when synoptic conditions were consistent at both 07:00 $\mathrm{h}$ and 19:00 h LST on the same calendar day. The goal of this practice was to examine $\mathrm{PM}_{2.5}$ data on days with a relatively consistent synoptic weather type, when impacts of the weather types are more clear.

This test case revealed differences in the average concentrations of $\mathrm{PM}_{2.5}$ by synoptic weather types (Table 7). Note that TD weather is not represented, which is an artifact of the brief sampling period. $\mathrm{CH}$ and $\mathrm{MH}$ weather types, on average, contain lower $\mathrm{PM}_{2.5}$ concentrations than the other weather types. AR weather contains the highest concentrations, with FOR-C, FOR-M, and FAR following close behind, respectively. To test whether these differences were significant, the Kruskal-Wallis (K-W) test was used (Keller et al. 1988). Although the sample sizes are small, the test revealed that there are significant differences in $\mathrm{PM}_{2.5}$ that are related to the synoptic weather types $(\mathrm{K}-\mathrm{W}$ statistic $=30.21 ; \mathrm{p}<0.001)$. $\mathrm{PM}_{2.5}$ are presumably advected from transportation sources along the USA Eastern Seaboard, as well as from industrial sources in the Ohio River Valley and the Tennessee River Valley. This occurs during AR and FAR weather types with south and southwesterly winds. During FOR-C and FOR-M, it is likely that a shallow boundary layer traps $\mathrm{PM}_{2.5}$ near the surface, leading to relatively high concentrations. During $\mathrm{CH}$ and $\mathrm{MH}$, the wind is generally from the north and west, bringing relatively cleaner Canadian air into the region, which is attributed to the lower density of industrial sources in southeastern Canada.
Similar results were found by Slater et al. (2002), who used this classification system in relation to the chemical composition of $\mathrm{PM}_{2.5}$ at a rural site in northern New Hampshire for a short sampling period. This study revealed that during AR and FAR synoptic conditions, $\mathrm{PM}_{2.5}$ concentrations were higher by at least a factor of 2, compared to $\mathrm{CH}$ conditions. During AR and FAR transport, ammonium sulfate accounted for most of the $\mathrm{PM}_{2.5}$. During times of air-mass transport from the north $(\mathrm{CH})$, ammonium sulfate and organic carbon contributed equally to the $\mathrm{PM}_{2.5}$. This is an indication of the predominance of sulfate in polluted air masses arriving from the south or southwest of New England, and the presence of naturally-formed organic aerosols during time of transport from cleaner sectors to the north.

\section{CONCLUSIONS AND DISCUSSION}

New England weather was classified into 9 all-inclusive weather types, using a manual procedure. $\mathrm{CH}$ and $\mathrm{MH}$ were the dominant weather patterns at Boston, while TD, GMR, and NEH weather types were least frequent, respectively. At 07:00 h LST, the coldest and driest weather type overall was $\mathrm{CH}$, while the hottest, most humid weather was generated by AR and FAR.

There were significant differences in $\mathrm{PM}_{2.5}$ concentrations resulting from different synoptic weather types. This classification system has other applications in applied climate research. For example, synoptic climate classifications have been used to analyze surface ozone concentrations (Comrie \& Yarnal 1992), insect migration patterns (Muller \& Tucker 1986), human mortality (Greene \& Kalkstein 1996), heavy rainfall distributions (Keim \& Muller 1992, Faiers et al. 1994, Keim \& Faiers 1995, Keim 1996), tornado outbreaks (Davis et al. 1997), percent of hourly rainfall totals (Faiers 1988), fluctuations in anticyclones (Rohli \& Henderson 1997), regional air-mass properties (Muller \& Willis 1983), coastal water level fluctuations (Childers et al. 1990), evaporation rates (McCabe \& Muller 1987), impacts of ENSO (McCabe \& Muller 2002) and climate change (Kalkstein et al. 1990). Furthermore, these weather types have applications in assessment of forest health and ecology, prediction of high and low temperature episodes, and dry and wet deposition of atmospheric aerosols. Jordan et al. (2000) have found interesting relationships between atmospheric chemistry and regional-scale atmospheric transport into the New England coastal region. It is therefore our hope that this synoptic climate classification system may be as useful in the northeastern USA as the Muller (1977) classification has been in the southeastern USA. 
Acknowledgements. This research was funded by the National Oceanic and Atmospheric Administration (NOAA), Office of Oceanic and Atmospheric Research (OAR) Grant no. NA97RP0309. J.F.S. was supported by the National Aeronautics and Space Administration (NASA) under the Earth System Science Fellowship Program (Grant NGT5-30349). The authors acknowledge Jane Fithian and Kristi Donahue for assistance with graphic production.

\section{LITERATURE CITED}

Babich P, Wang P, Allen G, Sioutas C, Koutrakis P (2000) Development and evaluation of a continuous ambient $\mathrm{PM}_{2.5}$ mass monitor. Aerosol Sci Technol 32:309-318

Bradbury JA, Keim BD, Wake CP (2002) U.S. East Coast trough indices at $500 \mathrm{hPa}$ and New England winter climate variability. J Clim 15:3509-3517

Bradbury JA, Keim BD, Wake CP (2003) The influence of regional storm tracking and teleconnections on winter precipitation in the northeastern United States. Ann Assoc Am Geogr 93:544-546

Childers DL, Day JW, Muller RA (1990) Relating climatological forcing to coastal water levels in Louisiana estuaries and potential importance of El Niño-Southern Oscillation events. Clim Res 1:13-42

Comrie AC (1996) An all-season synoptic climatology of air pollution in the U.S.-Mexico border region. Prof Geogr 48: 237-251

Comrie AC, Yarnal B (1992) Relationships between synopticscale atmospheric circulation and ozone concentrations in metropolitan Pittsburgh, Pennsylvania. Atmos Environ 26B:301-312

Davis RE, Kalkstein LS (1990) Development of an automated spatial synoptic climatological classification. Int J Climatol 10:769-794

Davis RE, Stanmeyer TM, Jones GV (1997) A synoptic climatology of tornadoes in Virginia. Phys Geogr 18: 383-407

Dockery DW, Pope CA, Xu X, Spengler JD, Ware JH, Fay ME, Ferris BG, Speizer FE (1993) An association between air pollution and mortality in six U.S. cities. N Engl J Med 329:1753-1759

Faiers GE (1988) A synoptic weather type analysis of January hourly precipitation at Lake Charles, Louisiana. Phys Geogr 9:223-231

Faiers GE, Keim BD, Hirschboeck KK (1994) A synoptic evaluation of frequencies and intensities of extreme three- and 24-hour rainfall in Louisiana. Prof Geogr 46: 156-163

Grant KE, Chuang CC, Grossman AS, Penner JE (1999) Modeling the spectral optical properties of ammonium sulfate and biomass aerosols: parameterization of relative humidity effects and model results. Atmos Environ 33: $2603-2620$

Greene JS, Kalkstein LS (1996) Quantitative analysis of summer air masses in the eastern United States and an application to human mortality. Clim Res 7:43-53

Halpert MS, Ropelewski CF (1992) Surface temperature patterns associated with the Southern Oscillation. J Clim 5: 577-593

Hay LE, McCabe GJ, Wolock DM, Ayers MA (1991) Simulation of precipitation by weather type analysis. Water Resour Res 27:493-501

IPCC (2001) Climate change 2001: the scientific basis. In: Houghton JT, Ding Y, Griggs DJ (eds) Contribution of Working Group I to the Third Assessment Report of the
Intergovernmental Panel on Climate Change. Cambridge University Press, Cambridge, p 289-348

Jordan CE, Talbot RW, Keim BD (2000) Water soluble nitrogen at the New Hampshire seacoast: $\mathrm{HNO}_{3}$, aerosols, precipitation, and fog. J Geophys Res 105:26403-26431

Kalkstein LS, Dunne PC, Vose RS (1990) Detection of climatic change in the Arctic using a synoptic climatological approach. J Clim 3:1153-1167

Keim BD (1996) Spatial, synoptic, and seasonal patterns of heavy rainfall in the southeastern United States. Phys Geogr 17:313-328

Keim BD, Faiers GE (1995) Heavy rainfall distributions by season: synoptic interpretations and quantile estimates. Water Resour Bull 32:117-124

Keim BD, Muller RA (1992) Temporal fluctuations of heavy rainfall magnitudes in New Orleans, Louisiana: 1871-1992. Water Resour Bull 28:721-730

Keller G, Warrack B, Bartel H (1988) Statistics for management and economics. Wadsworth, Belmont, CA

Kidson JW (2000) An analysis of New Zealand synoptic types and their use in defining weather regimes. Int $\mathrm{J}$ Climatol 20:299-316

Lamb HH (1972) British Isles weather types and a register of the daily sequence of circulation patterns, 1861-1971. Geophys Mem 116

Malm WC, Sisler JF, Huffman D, Eldred RA, Cahill TA (1994) Spatial and seasonal trends in particle concentration and optical extinction in the United States. J Geophys Res 99(D1):1347-1370

McCabe GJ, Muller RA (1987) Synoptic weather types: an index of evaporation in southern Louisiana. Phys Geogr 8: 99-112

McCabe GJ, Muller RA (2002) Effects of ENSO on weathertype frequencies and properties at New Orleans, Louisiana, USA. Clim Res 20:95-105

Muller RA (1977) A synoptic climatology for environmental baseline analysis: New Orleans. J Appl Meteorol 16: 20-33

Muller RA, Tucker NL (1986) Climatic opportunities for longrange migration of moths: In: Sparks AN (ed) Long-range migration of moths of agronomic importance to the United States and Canada: specific examples of occurrence and synoptic patterns conducive to migration. ARS-43, Agricultural Research Service, Department of Agriculture, Washington, DC, p 61-83

Muller RA, Willis JE (1983) New Orleans weather 1961-1980: a climatology by means of synoptic weather types. Miscellaneous Publ 83-1, School of Geoscience, Baton Rouge, LA

Rencher AC (1998) Multivariate statistical inference and applications. Wiley, New York

Rohli RV, Henderson KG (1997) Winter anticyclone changes over the Gulf Coast of the United States. Int J Climatol 17: 1183-1193

Ropelewski CF, Halpert MS (1987) Global and regional scale precipitation patterns associated with the El Nino/Southern Oscillation. Mon Weather Rev 115:1606-1626

Schwartz SE, Andreae MO (1996) Uncertainty in climate change caused by aerosols. Science 272:1121-1122

Serra C, Fernandez Mills G, Periago MC, Lana X (1999) Winter synoptic weather types in Catalonia (NE Spain) and their linkage with minimum temperature anamolies. Int J Climatol 19:1675-1695

Slater JF, Dibb JE, Keim BD, Talbot RW (2002) Light extinction by fine atmospheric particles in the White Mountains region of New Hampshire and its relationship to air mass transport. Sci Total Environ 287:221-239 
US EPA (1997a) Guidance for network design and optimum site exposure for $\mathrm{PM}_{2.5}$ and $\mathrm{PM}_{10}$. EPA-454/R-99-022, United States Environmental Protection Agency, Office of Air Quality Planning and Standards, Research Triangle Park, NC

US EPA (1997b) National ambient air quality standards for particulate matter-final rule. United States Envi-

Editorial responsibility: Robert Davis,

Charlottesville, Virginia, USA ronmental Protection Agency, Federal Register 62 (138): 38,651-38, 760; 40 CFR Part 50

Yarnal B (1993) Synoptic climatology in environmental analysis. Belhaven Press, London

Zielinski GA, Keim BD (2003) New England weather New England climate. University Press of New England, Hanover, NH

Submitted: August 11, 2001; Accepted: January 4, 2005

Proofs received from author(s): February 15, 2005 